\title{
Smart Grid for a Sustainable Future
}

\author{
G. M. Shafiullah", Amanullah M. T. Oo, A. B. M. Shawkat Ali, Peter Wolfs
}

Higher Education Division, School of Engineering and Technology, Central Queensland University, Rockhampton, Australia. Email: "g.shafiullah@cqu.edu.au,gmsbd@yahoo.com

Received September 14 $4^{\text {th }}$ 2012; revised October 14 ${ }^{\text {th }}$, 2012; accepted October $21^{\text {st }}, 2012$

\begin{abstract}
Advances in micro-electro-mechanical systems (MEMS) and information communication technology (ICT) have facilitated the development of integrated electrical power systems for the future. A recent major issue is the need for a healthy and sustainable power transmission and distribution system that is smart, reliable and climate-friendly. Therefore, at the start of the $21^{\text {st }}$ Century, Government, utilities and research communities are working jointly to develop an intelligent grid system, which is now known as a smart grid. Smart grid will provide highly consistent and reliable services, efficient energy management practices, smart metering integration, automation and precision decision support systems and self healing facilities. Smart grid will also bring benefits of seamless integration of renewable energy sources to the power networks. This paper focuses on the benefits and probable deployment issues of smart grid technology for a sustainable future both nationally and internationally. This paper also investigates the ongoing major research programs in Europe, America and Australia for smart grid and the associated enabling technologies. Finally, this study explores the prospects and characteristics of renewable energy sources with possible deployment integration issues to develop a clean energy smart grid technology for an intelligent power system.
\end{abstract}

Keywords: Smart Grid; Renewable Energy; Grid Integration; Wind Energy; Solar Energy

\section{Introduction}

Existing power systems can be considered as a major reason for greenhouse or global warming effects that cause environmental impacts due to use of fossil fuels, especially coal. In contrast to fossil fuels, renewable energy (RE) offers alternative sources of energy which are in general pollution free, technologically effective and environmentally sustainable. There is unprecedented attention to RE, particularly solar and wind energy, which provides electricity without giving rise to carbon dioxide emissions. However, most of the current transmission and distribution networks are considered as "dumb" systems as they are not capable of feeding back the intelligent data required for a modern grid operation [1,2]. The existing electricity grid has no potential to offer adequate services addressing energy efficiency, reliability and security, or the integration of RE at the scale needed to meet the clean-energy demand for the future [3].

Therefore, introduction of smart grid technology is an essential requirement that reduces overall greenhouse gas (GHG) emissions with demand management that encourages energy efficiency, improves reliability and manages power more efficiently and effectively. Smart grid is the combination of centralized bulky power plants and

${ }^{*}$ Corresponding author. distributed power generators that allows multi-directional power flow and information exchange. Its' two-way power communication systems create an automated and energy-efficient advanced energy delivery network. On the other hand, in traditional power systems, power flows only in one direction, i.e., from generating station to customers via transmission and distribution networks [1-6].

The smart grid is a broad collection of technology that delivers an electricity network with flexibility, accessibility, reliability and economy. Smart Grids are sophisticated; they can digitally enhance power systems where the use of modern communications and control technologies allows greater robustness, efficiency and flexibility than today's power systems [1-6]. Brief comparisons between an existing grid and a smart grid are given in Table $\mathbf{1 .}$

Smart grid technologies are still new and many are in the development stage. However, it is anticipated that smart grid technology will be play a self-regulatory role in power system networks due to its many advantages as given below $[6,7]$.

\subsection{Intelligent and Efficient}

Smart grid is capable of sensing system overloads and rerouting power to prevent or minimize a potential outage. It is efficient and potentially able to meet increasing consumer demand without adding any infrastructure. 


\subsection{Accommodating}

Due to its robustness, smart grid can accommodate energy from fuel sources as well as RE sources and adopt any new technologies for a climate-friendly society.

\subsection{Reduce Global Warming}

Possible to integrate large-scale RE into the grid that reduces global warming as well as GHG emission.

\subsection{Repairing and Maintenance}

Automatic maintenance and operation increases the efficiency of the power network. Moreover, predictive maintenance and self-healing reduces system disturbances.

\subsection{Reliability}

Improves power quality and reliability as well as enhances capacity of existing network.

\subsection{Distributed Generation}

Accommodates distributed power sources efficiently which reduces energy costs, GHG emissions and energy crisis issues world-wide.

\subsection{Consumer Focus}

Consumers can customize their energy uses based on individual needs, electricity prices and environmental concerns.

\subsection{Security}

With the adoption of security features in smart grid, the network is safer from cyber-attack and any unwanted tampering and natural disaster.

\subsection{Quality-Focused}

Ensures power quality of the network by reducing voltage fluctuation (sag, swell and spikes) and harmonic effects in the network.

\subsection{Technology}

New concepts and technologies will be developed that enhance power system infrastructure and accommodate new opportunities in innovation.

\subsection{Socio-Economic Development}

This new technology will open new doors in the power sector and communication arena. It will play an active role in socio-economic development as well as create job opportunities.

Therefore, this study explores the research undertaken
Table 1. Comparison between existing grid and smart grid.

\begin{tabular}{cc}
\hline Existing grid & Smart grid \\
\hline Mostly electromechanical & Digital in nature \\
One-way communication & Two-way communication \\
Mostly centralized generation & Distributed generation \\
Sensors are not widely used & Sensors are widely used \\
Lack of monitoring; only manual & Digital self-monitoring \\
Failures and blackouts & Adaptive and intelligent \\
Lack of control & Robust control technology \\
Less energy-efficient & Energy-efficient \\
Usually not possible to integrate & Possible to integrate large-scale RE \\
RE & Customers can check uses and \\
Customers have less scope to & modify \\
\hline
\end{tabular}

for the deployment of smart grid technology worldwide with their implementation challenges. The smart grid deployment issues that include: smart grid infrastructure, communication technologies, potential barriers, and development of possible viable solutions for such implementation were also explored. This study also aimed at developing an integrated platform to continuously investtigate the impacts of RE on the smart grid which will assist the power utilities to develop an improved national power grid that will help to build a sustainable society. The proposed integrated platform comprises with feasibility study to investigate the prospects of RE in Australian context; prediction model to assess the energy generation from RE sources; real-time experiments and simulation model to explore the impacts on integrating RE into the smart grid. This paper is organized as follows: Section 2 discusses the smart grid initiatives worldwide; smart grid deployment issues are represented in Section 3. Section 4 presents integration of renewable energy with smart grid. Section 5 concludes the paper with future directions.

\section{Smart Grid Initiatives Worldwide}

Substantial research, planning and development are required for the deployment of a new smart infrastructure to integrate large-scale RE into the energy mix. The European and North American vision for Smart Grid technology has evolved over the past decade and has begun to achieve a level of maturity. In the next two sub-sections, the international policy initiatives taken by Europe, the USA and Australia for smart grid developments for a sustainable future power system have been explored.

\subsection{Smart Grid Developments in the USA and Europe}

The USA's Center for American Progress imparts a view 
of a clean-electricity or clean energy "pipeline" which produces large scale renewable electricity, delivers electricity nationwide on a new high capacity grid, deals with all power generation and distribution with new robust information technology methods and allows consumers to contribute energy to the grid [2]. In April 2003, the Department of Energy (DOE), USA declared its "Grid 2030" mission, the vision of which was: Grid 2030 energizes a competitive North American Market place for electricity. It connects everyone to abundant, affordable, clean, efficient and reliable electric power anytime, anywhere. It provides the best and most secure electric services available in the world [8].

To fulfill this vision, Electrical Power Research Institute's (EPRI's) Intelligrid ${ }^{\mathrm{SM}}$ has undertaken an initiative to develop the technological foundation for a smart power grid that links electricity systems with communication and computer technology to achieve tremendous gains in reliability and customer services [9]. To achieve this, Intelligrid architecture offers a methodology, tools and recommendations for integrating data networks and equipment that enable interoperability between products and systems [10]. Figure 1 shows a schematic diagram of EPRI's Intelligrid model.

The US Department of Energy Office of Electric Transmission and Distribution's GridWise ${ }^{\mathrm{TM}}$ program [11] is an industry alliance with a vision for the future electric system built upon the primary principle that information technology will intensely transform the planning and operation of the power grid. The GridWise program has a focus on:

- Communications architecture and standards

- Simulation and analysis tools

- Smart technologies

- Test beds and demonstrated projects

- New regulatory, institutional and market frameworks

The impact of renewable energy and smart grid interactions were investigated by National Grid, USA [12] on the US power networks. A typical scenario of their proposed model is given in Figure 2.

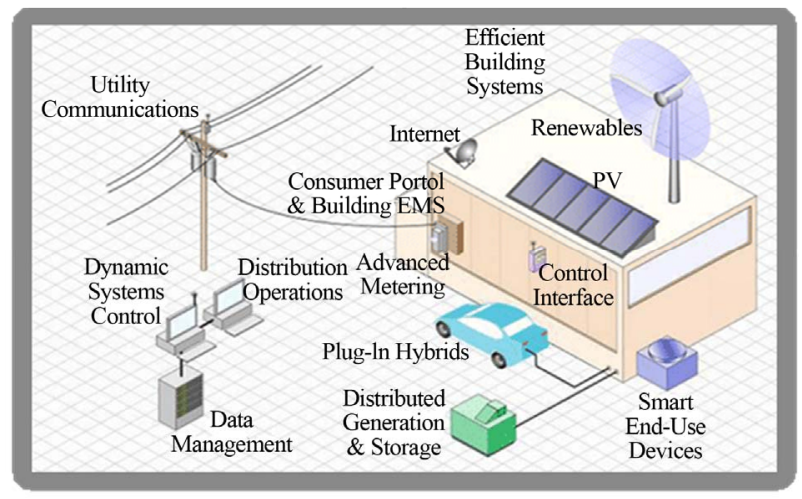

Figure 1. A typical scenario of EPRI's intelligrid model [9].
The European Union Advisory Council established Smart Grids European Technology Platform in 2005, to develop the weak grid with smart grid technology and overcome the drawbacks in the existing power systems. The smart grid European Technology Platform [13] vision is that Europe's electricity network must be flexible (fulfilling customer needs), accessible (access to all network users, particularly for RE sources and high efficiency local generation with low carbon emission), reliable (assuring security and quality of supply) and economic (cost and energy efficient management) to facilitate Europe's electricity grids to meet the challenges and opportunities of the $21^{\text {st }}$ century and fulfill the expectations of society. The key requirements to achieve the vision include [13]:

- Creating technical solutions to be applied promptly and cost effectively that allow grids to accept power additions from all energy sources.

- Harmonizing regulatory and commercial structures in Europe to facilitate cross-border dealing of both power and grid services, ensuring that they will accommodate a wide range of operating conditions.

- Launching technical standards and protocols that will ensure open access.

- Developing information, computing and telecommunication systems.

- Ensuring the successful interfacing of new and old equipment designs.

The future network vision of the European Technology Platform is shown in Figure 3.

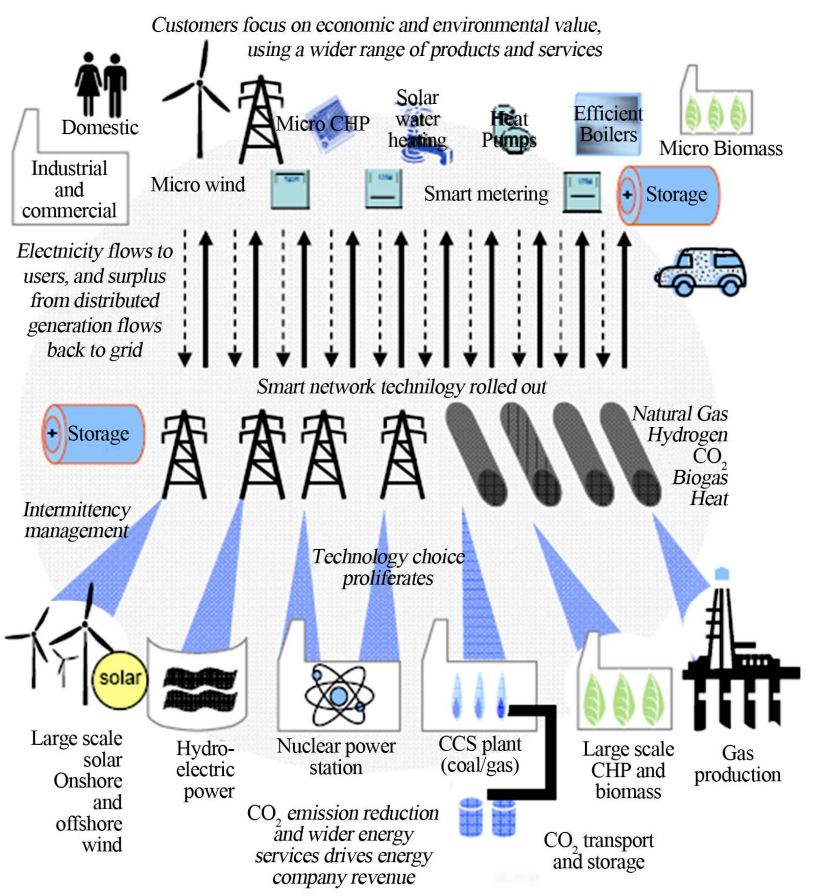

Figure 2. The smart grid evolution-A proposed model by national grid, USA [12]. 


\subsection{Smart Grid Developments around Australia}

Australia's energy prices are comparatively low as more than three-quarters of the country's electricity is generated by coal-fired plants. Hence, Australia is lagging behind compared to the USA and Europe in an attempt to integrate RE sources and build smart grid infrastructure. However, Australia's reliance on coal-fired power gives it one of the world's highest per-capita GHG emission rates. Coal imposes environmental costs in the form of greenhouse gases, including 200 million tons of carbon dioxide equivalents $\left(\mathrm{CO}_{2}-\mathrm{e}\right)$ released in 2008, more than a third of Australia's total $\mathrm{CO}_{2}$-e emissions [1,2]. Therefore, it is essential to strengthen the Australian economy by fostering new generation transmission and distribution systems for efficient use of low-carbon electricity, as the current high-voltage transmission grid imposes significant constraints on the deployment of new RE such as wind, solar and geothermal power. Current monitoring and control technology on both transmission and distribution networks is fragile [2]. The lack of smart technology to provide utilities and consumers with better information in real time impair the security and capability of the entire electricity system $[1,2]$. Therefore, it is necessary to integrate information processing and communications into power systems to create a unified smart grid that includes generation, transmission, distribution, retail and end-use.

The Australian Government has already taken the initiative with huge scale investment to develop their electricity infrastructure as well as deploy smart grid technology to integrate large scale RE into the grid [14]. Table 2 shows the current and future investments in Australia by State in which the green bars depict current periods and red bars future periods. Recent determinations for the ACT and NSW increase expenditure allowances by $70 \%$ over the preceding funding period [14]. Similar increasing trends are also observed in other States.

The Australian government has adopted the Smart Grid, Smart City initiative and invested \$100 million to create a large scale smart grid platform, which optimizes societal benefits by prioritizing applications and under-

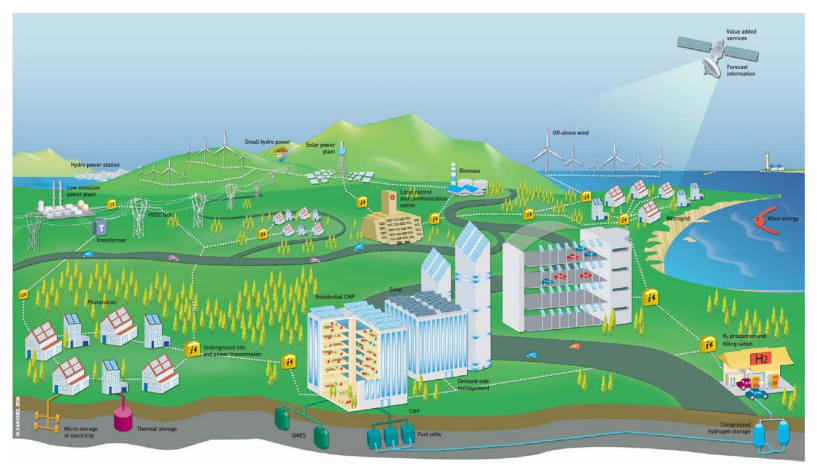

Figure 3. Future network vision [13].
Table 2. Investments by state: current and future [14].

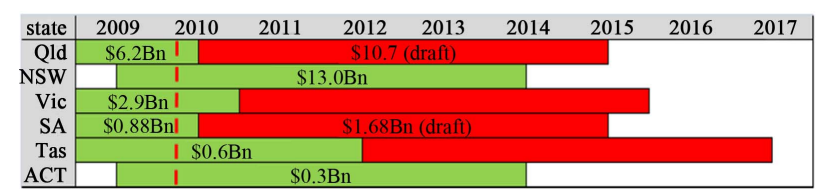

taking a commercial scale deployment that tests the business case and main technologies [1]. It investigates synergies with other Australian Government programs and related infrastructure projects, builds awareness of the benefits and obtains buy-in from industry and customers. This project seeks to overcome major hurdles by supporting the adoption of smart grid technologies across Australia and build an innovative solution [1]. The aim is to link 9500 homes to a smart grid to allow residents to see real-time electricity usage in their houses which helps them to optimize the use of electricity. The Energy Australia Consortium is working hard to complete the project within the allocated timeframe and has already connected a large number of households with significant telecoms backbone infrastructure. The project will also evaluate smart grid applications in integrating RE and electric vehicles. The project is expected to be completed by $2013[15,16]$.

In Australia, the Intelligent Grid Program [17] was commenced on 19 August 2008, being recognized under the CSIRO's Energy Transformed Flagship. The main focus of the program is to reduce GHG emissions [1]. The Townsville Solar City Project managed by the Australian Government and Ergon Energy (a local Queensland based electricity distribution utility organization) has conducted 742 residential and commercial assessments, and installed 1445 smart meters, $160 \mathrm{~kW}$ of solar panels and eight advanced energy storage systems. A range of schemes that aim to cut down wasteful energy usage, increase solar energy usage and reduce GHG emissions by more than 50,000 tonnes has been undertaken in the project [18]. Western Power's (a local Western Australia based transmission and distribution utility organization) Solar City program includes a PV saturation trial to test the effect of distributed generation on the network. The Solar cities program has assisted many distributors to realize the problems of inverter connected renewable distributed generation (DG). This analysis included smart meters that collect bi-directional data to capture how much power the distributed generator is feeding back to the grid $[1,19]$.

Recently, the Australian government has adopted the Clean Energy Initiative (CEI) for the operation of a range of renewable and clean energy technologies to reduce GHG emissions and meet rising electricity demand. The CEI program consists of Carbon Capture and Storage (CCS) initiatives, Solar flagships, the Australian Solar Institute (ASI), the Australian Centre for RE (ACRE) and 
the RE Future Fund (REFF) [20].

\section{Smart Grid Deployment Issues}

With the initiative of international policy makers and Governments, research communities, industries, and scientists are working together to develop the smart grid and its enabling technologies for a robust power system worldwide. In this section, three major systems required to deploy smart grid technologies in the power system networks are explored, comprising the infrastructure of smart grid technologies, the associated communication technologies and standards and, finally, a smart grid model for the future.

\subsection{Smart Grid Infrastructure}

The smart grid is capable of integrating RE into the grid and delivering power in more efficient ways by utilizing modern information technologies as well as smart infrastructure and control management systems. Fang et al. [5] conducted an extensive survey in which the smart grid and its enabling technologies were divided into three major sections:

\subsubsection{Smart Infrastructure System}

Smart infrastructure system comprises the smart energy subsystem, the smart information subsystem and the smart communication subsystem. Electricity generation, transmission and distribution, as well as consumption of electricity facilities, are incorporated in the smart energy subsystem. The smart information subsystem comprises smart metering, advanced monitoring and management of the smart grid network. The smart communication subsystem is responsible for wired and wireless communication between networks, devices and applications to established connectivity in the network [5].

\subsubsection{Smart Management System}

Advanced management, monitoring and control services are provided by the smart management system in smart grid. With the development of advanced management and monitoring applications and control services, the smart grid technology will be smarter and play an active role in developing a sustainable power system. The smart management system comprises energy efficiency improvement, supply and demand balance, emission control, operation cost reduction and utility maximization. Modern machine learning and other optimization tools are used to make a robust smart management system [5].

\subsubsection{Smart Protection System}

Reliability, failure protection, security and privacy protection services of the grid are provided by the smart protection system in smart grid. Integration of advanced protection equipment and monitoring tools ensures network reliability, security and privacy. In addition to smart infrastructure design, smart management and smart protection systems address efficient management and failure protection, cyber security and privacy in the network. Figure 4 shows a representation of the typical technological architecture of the smart grid [5].

\subsection{Smart Grid Communication Technologies and Standards}

Smart grid technologies are basically used for smart power delivery which is a combination of current and advanced new technologies. Smart grid technologies include automation technologies for smart power delivery, new advanced communication technologies, distributed energy and storage technologies such as solar, wind turbines and fuel cells, advanced metering infrastructure (AMI), power electronics-based controllers and appliances and devices which are demand-response ready [3]. Smart grid has enhanced and robust communication and computing capabilities that makes this an attractive technology for future power systems.

Smart grid ensures today's key requirement of reliable delivery of power from the generating stations to end-

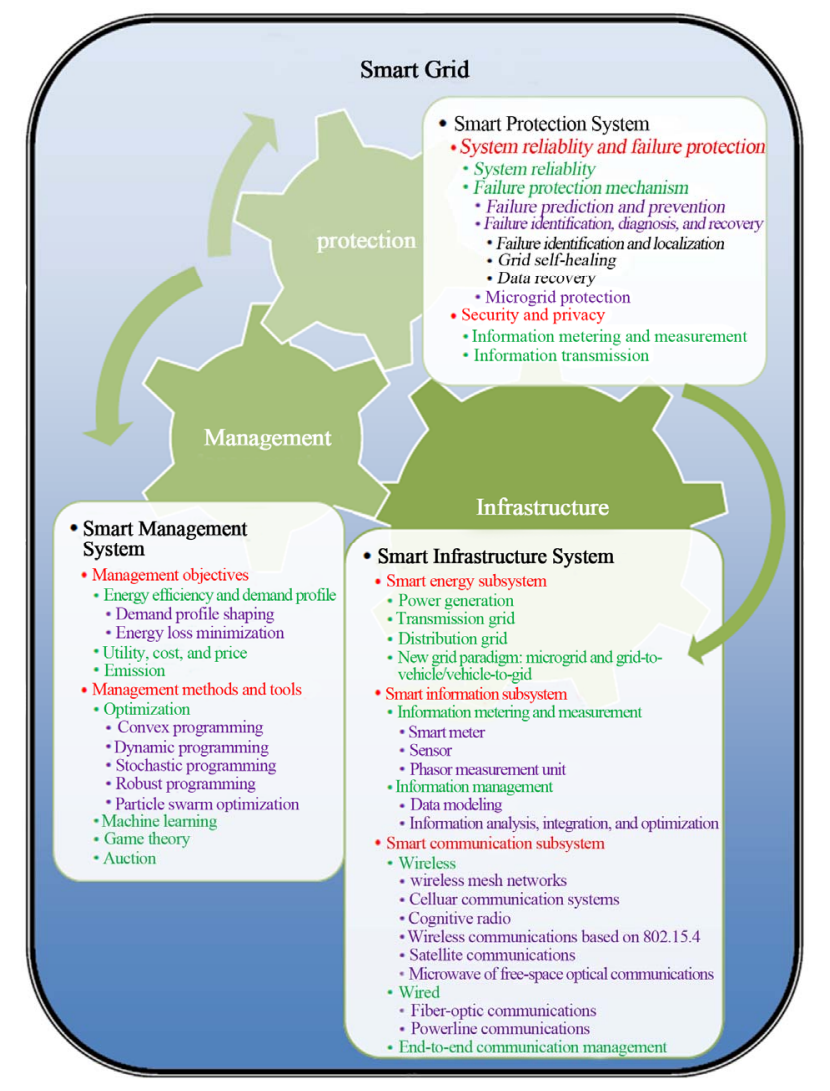

Figure 4. The typical classification of the smart infrastructure, the smart management and the smart protection system [5]. 
users by introducing modern information and communication standards and technologies [21]. Recent studies [21-23] show that both wired and wireless communication systems are used in smart grid for data communication between smart meters and electric utilities. The data flow from sensors and electrical appliances to smart meters can be accomplished by power line communication or wireless communication. Cellular technologies or the internet can be used to communicate between smart meters and a utility's data centre. A typical smart grid architecture proposed by Gungor et al. [21] is presented in Figure 5.

Popular communication technologies that are used in smart grid are ZigBee, wireless mesh, cellular network communication, power line communication (PLC) and digital subscriber lines (DSL) though they all have some advantages and disadvantages. Wired technologies, such as PLC, DSL and optical fiber are reliable and secured, however, they require high capital cost due to large-scale installation and maintenance. On the other hand, wireless technologies require less installation cost though they have problems with bandwidth and security [21]. Ensuring reliability and security in the communication medium or path is essential for appropriate end-to-end data communication. Smart grid should be secure enough to prevent cyber-attacks and have appropriate bandwidth allocation with an advanced control system that provides stability and availability. Wireless technologies with controlled bandwidth and security are a preferable option as it is possible to deploy large scale smart grid with reduced costs, while wired technologies with high capacity and security require high costs [24]. However, considering costs, robustness and reliability, a hybrid communication technology combining both wired and wireless techniques has been used.

Researchers are working together to investigate new communication technologies, applications and standards for a secure, reliable, robust and efficient smart grid

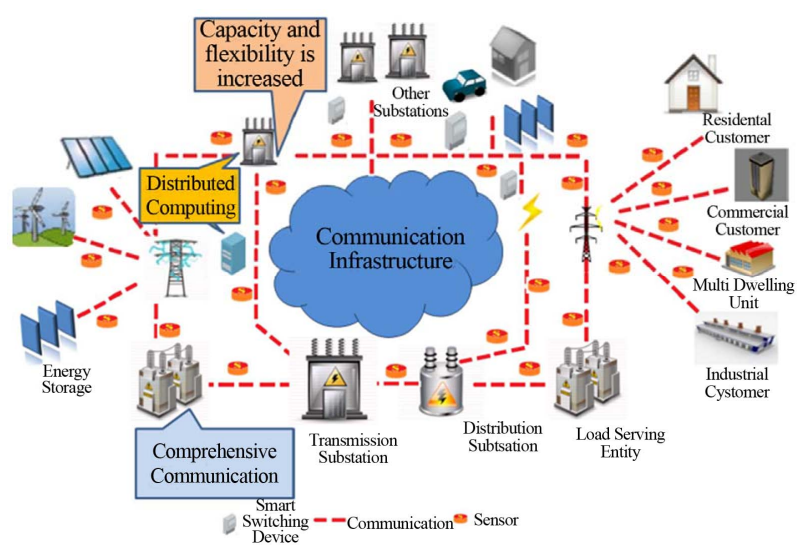

Figure 5. Smart grid network with modern communication technologies [21]. network. The goal of smart grid standards is to provide seamless interoperability between systems, information security, a compact set of protocols and communication exchange [25]. The European Technology Platform, The American National Standards Institute, the International Electrotechnical Commission, The Institute of Electrical and Electronics Engineers, the International Organization for Standardization, the International Telecommunication Union and the Third Generation Partnership Project are the recognized standard development organizations working together and focused on smart metering functionalities and communication interfaces.

\subsection{Smart Grid Model}

Recently, Zahedi [3] proposed a smart grid model that is useful in understanding the architecture and power flow of the smart grid as shown in Figure 6. The major parts of the model are:

\subsubsection{Central Power Stations}

Power is generated from various energy sources in the central power stations. The sources of energy are renewable such as solar, wind and hydro, and non-renewable such as coal-fired, nuclear and gas turbine, etc. Suitable storage facilities are also included in the power stations.

\subsubsection{Transmission Network}

Bulk high-voltage electricity passes through transmission lines over long distances in the smart grid. Smart equipment devices are used to transfer electricity from transmission substations to distribution substations.

\subsubsection{Distribution Network}

The distribution network model delivers electricity to end-users at low-voltage levels. In the distribution network, there are bi-directional power flows as the system absorbs energy from the consumers who generated power through roof-top solar panels, etc. The distribution net-

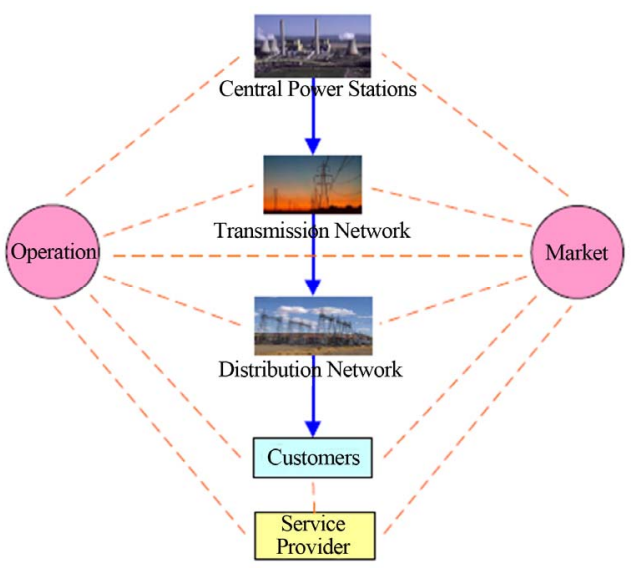

Figure 6. Typical smart grid model [3]. 
work connects smart meters and all intelligent devices and controls them through a two-way wireless and wired communication network $[2,26]$.

\subsubsection{Market Domain}

In the model, the market domain both comprises and coordinates all the participants in electricity markets serviced by the smart grid.

\subsubsection{Service Provider Domain}

Service providers supply services to both customers and power utilities.

\subsubsection{Operation Domain}

The operation domain maintains and controls the electricity flow of the other domains within the smart grid.

\subsubsection{Customer Domain}

The customer domain connects the residential, commercial and industrial customers to the electric distribution network through smart meters.

This model is expected to be used as the basis for the design of smart grid infrastructure that defines characteristics, requirements, interfaces and performance of the grid [3].

Therefore, it can be concluded that International policy makers, Government, industrialists, and researchers are working together to deploy smart grid technology worldwide for a sustainable robust and secured power systems for the future. The utilization of smart grid functions allows for larger saturation of variable energy sources through more adaptable management of the system [27]. However, there are a number of challenges in integrating $\mathrm{RE}$ sources with the smart grid enabled power systems.
Therefore, the authors are currently investigating the characteristics and prospects of RE sources, as well as impacts on integrating $\mathrm{RE}$ with the smart grid, to develop a clean-energy smart grid technology for a sustainable future both nationally and internationally. A snapshot of the work in progress is presented in the next section.

\section{Integration of RE with Smart Grid}

The advances of smart grid technologies have guided the growth of information technology based energy management and climate change mitigation systems. The authors are currently investigating the benefits and probable mixing of RE into the smart grid so as to build up a clean energy system for a sustainable future. This project looks at the strategic impacts of integrating RE sources with the grid together with the analysis of the possible limitations, and developments of probable feasible solutions, for such implementation. An integrated platform will be developed to continuously investigate the effects of RE on the smart grid which will support the power utilities in developing an improved national power grid.

To investigate the impact of RE sources within a smart grid, the methodology and approach to carry out the research includes: investigation of existing transmission and distribution networks; conducting a feasibility study on integrating RE sources with the existing distribution networks; real-time experiments using RE sources; investigation of the potential challenges of RE inputs to a smart power grid; and finally, development of a tool or platform to continuously investigate the impacts of $\mathrm{RE}$ on smart grids. Figure 7 presents the framework of the proposed study. In the following subsections, details of each approach are presented.

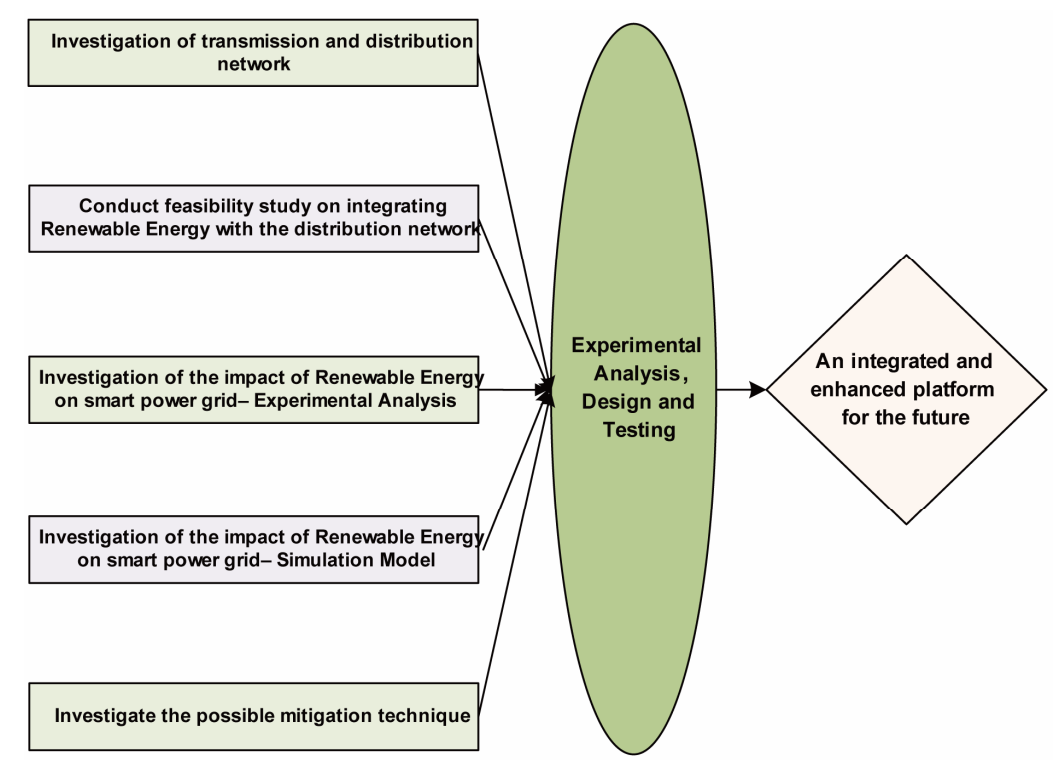

Figure 7. Block diagram of the planned methodology framework. 


\subsection{Prospects of RE in the Australian Context}

Hybrid renewable energy models were developed to investigate the prospects of renewable energy, in particular wind and solar energy. Suitable locations for both wind and solar energy generation were investigated using statistical analysis. To assess the performances of different hybrid systems in the study, optimal systems and the sensitivity analysis were undertaken using the HOMER simulation tool [28]. The models were simulated based on the sensitivity variables of wind speed, solar irradiation and grid electricity price. Net present cost (NPC), cost of energy (COE) and renewable fraction (RF) [29] were estimated as model outputs to evaluate the performances of the studied models. PV/wind/grid-connected, PV/grid-connected, wind/grid-connected and only grid-connected systems were evaluated to analyze the potentialities of RE in Australia. The details of the study are available in Ref. [30].

From the statistical analysis it was estimated that, for wind energy generation, Tasmania ranked 1 (most suitable) and the Northern Territory ranked 7 (least suitable) out of the seven States of Australia. On the other hand, it was estimated that the Northern Territory ranked 1 and Tasmania ranked 7 out of the seven States of Australia for solar energy generation.

From simulation analysis, it was seen that the wind turbine and PV module required almost $80 \%$ of the total cost as capital expenditure. However, most of the operating cost is required for the grid components and converters, and RE sources require less operating expenditure which is one of their most useful features.

It was observed that Flinders Reef, Queensland, Australia is the most suitable place considering the energy generation from both solar and wind resources, with a contribution from RE of $90 \%$ as shown in Figure 8. From that Figure, it can be seen that a wind/grid-connected system is more suitable than the PV/wind/gridconnected system. It is also seen that a wind/grid-connected power system is economically feasible with a minimum total NPC of $\$ 75,789$ and a minimum COE of $\$ 0.162 / \mathrm{kWh}$, while a grid-connected only power system requires a minimum total NPC of $\$ 184,055$ and a minimum COE of $\$ 0.394 / \mathrm{kWh}$.
This feasibility study evaluated the total yearly emissions from $\mathrm{PV} /$ wind/grid-connected, standard grid-connected, wind/grid-connected, and PV/grid-connected systems. Figure 9 presents the yearly emissions of $\mathrm{CO}_{2}, \mathrm{SO}_{2}$, and $\mathrm{NO}_{2}$ for the developed hybrid RE model at seven selected locations in Australia. For example, for Ceduna in South Australia, the standard grid-connected only system emitted 34,018 $\mathrm{kg} \mathrm{CO}_{2}$ per year; on the other hand, a $\mathrm{PV} /$ wind/grid-connected system emitted only 10,842 kg/yr. A PV/grid-connected system emitted 32,794 kg $\mathrm{CO}_{2}$ per year and a wind/grid-connected system emitted only 11,773 kg/yr. Figure 9 shows that a small number of places have negative emissions especially for wind/ grid- and PV/wind/grid-connected systems; i.e., these systems sell more power than they purchase from the grid as they generate surplus electricity [30].

Therefore, it can be concluded that large-scale penetration of RE not only reduces the cost of energy and assists with the energy-crisis worldwide, but also reduces emissions which will have a major role in building a sustainable climate-friendly future both nationally and internationally. However, it was found that wind energy has more potentialities compared to solar energy.

Based on the performance metrics, optimization and sensitivity analysis, it was observed that most of the selected locations have prospects for solar and wind energy generation. However, few locations perform exceptionally well for wind energy generation and few locations are greatly capable for solar energy generation.

\subsection{Prediction Model of RE}

To facilitate the introduction of a large number of RE sources into the grid, a careful evaluation of the attributes of each RE source is crucial, in particular the variability of its production with changing weather conditions. The useful utilization of wind and solar energy requires a detailed knowledge of the wind and solar features at the particular location, and the distribution of wind speeds and solar irradiation is important for the design of wind farms and solar plants, and power generators. However, adequate information is not always available over reasonable periods of time on the wind power or solar plant sites for power system planning purposes. Therefore,

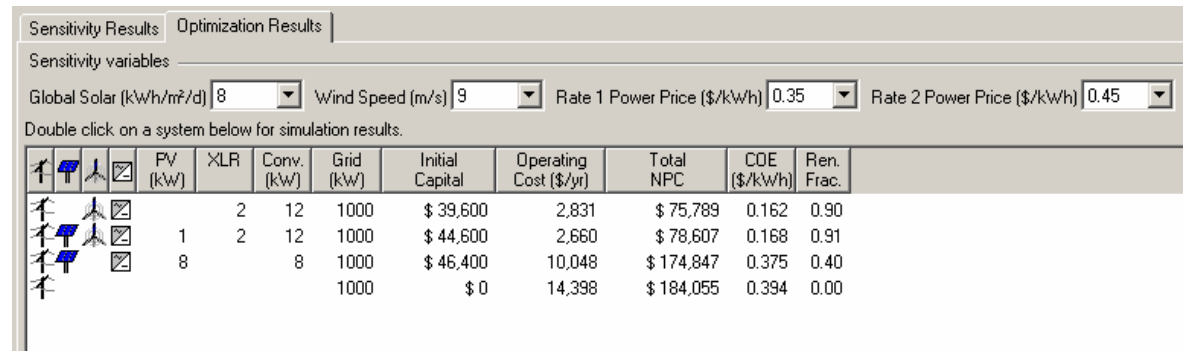

Figure 8. Optimization results for flinders reef, QLD with $8.0 \mathrm{kWh} / \mathrm{m}^{2} / \mathrm{d}$ solar radiation, $9.0 \mathrm{~m} / \mathrm{s}$ wind speed [30]. 


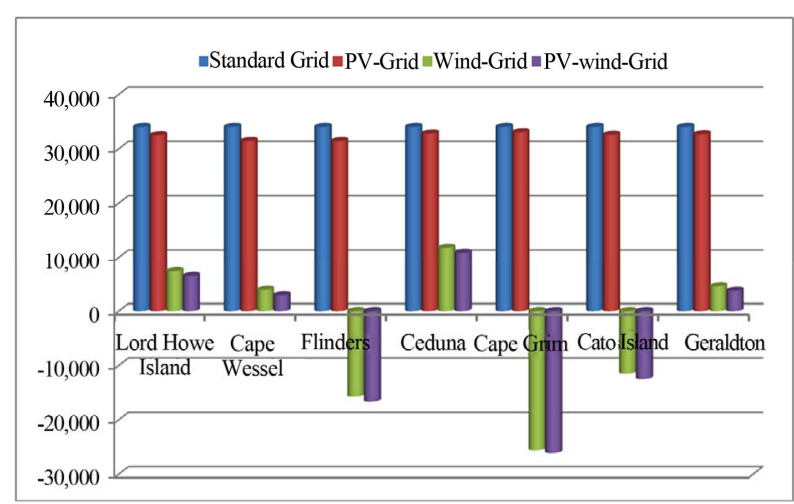

Figure 9. $\mathrm{CO}_{2}$ emissions at seven selected locations for the four systems studied [30].

prediction models were developed that estimates the typical power generation available separately from wind and solar sources in advance using modern machine learning techniques.

This study was conducted using ten different regression algorithms to forecast the daily distribution of solar irradiation and hourly distribution of wind flow. Metabased learning Random Sub Space (RSS), and RegressionByDiscretization(RegDes), Regression-based learning linear regression (LR), simple linear regression (SLR), Statistical learning based algorithm sequential minimal optimisation (SMO) regression (SMOReg), and Neural Network based multilayer perception (MLP), RBFNetwork (RBFN), Lazy-based learning IBK, Treebased learning M5Rules and RepTree with bagging techniques [31-33] were considered in this study for developing the prediction model. The most suitable algorithm was proposed based on the performance metrics [31] of the algorithms that include the correlation coefficient (CC), mean absolute error (MAE), root mean square error (RMSE) and computational complexity. The Waikato Environment for Knowledge Analysis (WEKA) learning tool [34] was used to evaluate the prediction accuracy. Proposed algorithms with classical data splitting options were used to predict the daily distribution of solar radiation and hourly distribution of wind speed. Popular statistical analyses were carried out to select the most suitable algorithm to predict solar irradiation and wind speed as well as energy generation from these resources. Details of the model are available in Reference [35].

Initially, models were developed using ten regression algorithms with the collected hourly wind data to predict hourly distribution of wind flow. Model results showed that overall prediction accuracy is fairly similar; however no algorithm performs the best for all of the estimated attributes. Figure 10 shows that IBK, RBFN and RegDes predicted with highest accuracy. CC is the least accurate for the model developed with linear regression (LR). In terms of MAE and RMSE, the model developed with RepTree with Bagging techniques is the best.

Rankings for the algorithms have been estimated and it is observed that Bagging technique has ranked 1, while RBFN has ranked 2 and RegDes has ranked 10. Finally, relative weighted performance was measured considering average ranking accuracy and computational complexity using the following equation:

$$
Z=\alpha a_{i}+\beta t_{i}
$$

here, $\alpha$ and $\beta$ are the weight parameters for ranking average accuracy against computational complexity. The average accuracy and computational complexity are denoted by $a_{i}$ and $t_{i}$ respectively. From Figure $\mathbf{1 1}$ it is shown that, considering computational complexity and average accuracy, Bagging technique is the best choice for all $\beta$ values and RBFN is the second for this application. The model developed with RegDes performs the worst for this application. It has also been observed that MLP requires more computational time compared to other algorithms.

Similar models have been developed using the same ten regression algorithms with solar irradiation data. From the results, it was seen that the models developed

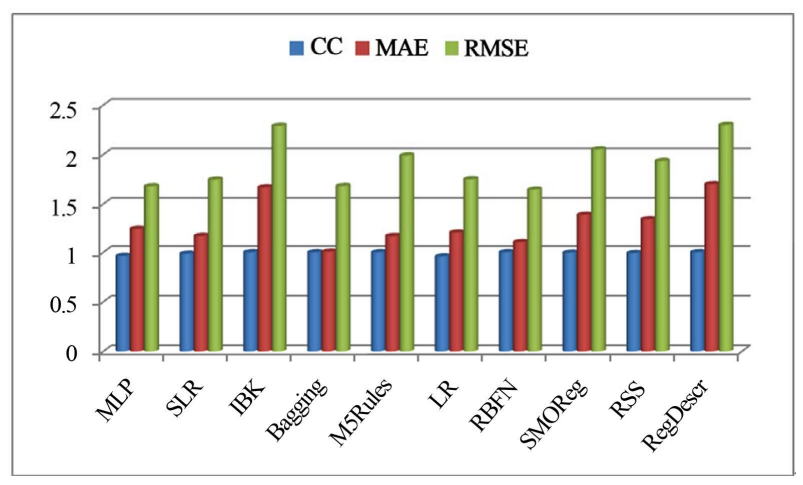

Figure 10. Comparisons of performance metrics with different algorithms for prediction of houlry wind speed [35].

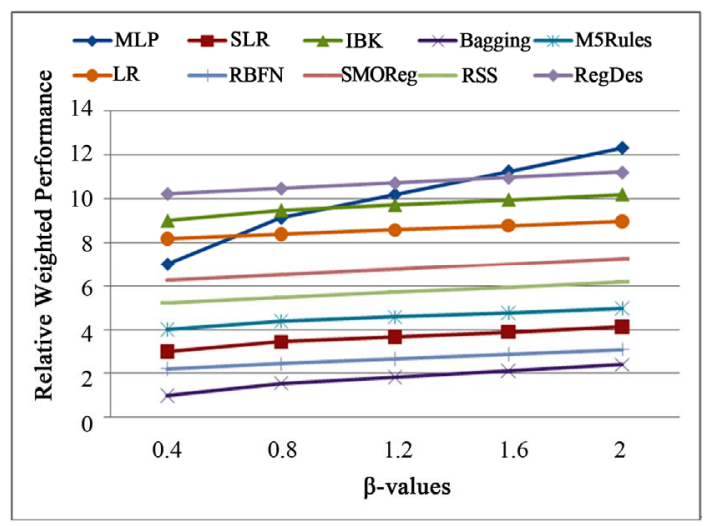

Figure 11. Overall weighted performance of the algorithms with respect to $\beta$ for wind speed data [35]. 
with RSS and Bagging technique with RepTree are respectively the first and second prefered to predict daily solar irriadiation as well as solar energy production.

\subsection{Impacts on Integrating RE into the Grid}

To analyze the impacts of RE integration, in particular the impacts of large-scale PV integration into the grid, experiments were undertaken at CSIRO, Newcastle, Australia [36] using their Renewable Energy Integration Facility (REIF). Voltage instability and harmonic impact on the network was explored with varying PV saturation and load conditions. From this work, it was possible to measure voltage instability, harmonic effects, reactive and real power with the increases of PV saturation and increases of micro turbine capacity with varying load conditions. A detail of the study is presented in Reference [37].

Considering the flexibility and robustness of the experiments, two experiments were carried out with different case scenarios. Experiment 1 was performed with $11.31 \mathrm{~kW} \cdot \mathrm{PV}$ saturation with varying micro turbine and load conditions. On the other hand, Experiment 2 was carried out with $7.5 \mathrm{~kW} \cdot \mathrm{PV}$ saturation with varying micro turbine and load conditions. From the experimental results, it was show that the harmonic content of the network increases with the increase of PV saturation and system size. Experimental results also show that significant voltage instability occurs into the system and the power factor is reduced with increasing PV penetration.

Neutral currents for $11.31 \mathrm{kV}$ and $7.5 \mathrm{kV} \cdot \mathrm{PV}$ saturation are shown in Figure 12. From that Figure, it can be seen that the neutral current fluctuates significantly from the original sinusoidal wave which indicates that the system is unbalanced and introduces a large amount of harmonics into the system. It has also been found that harmonics injection increases with increasing PV saturation.

In this study, Fast Fournier Transform (FFT) was ap- plied to investigate harmonic effects in the distribution system. Based on the Australian standard, $50 \mathrm{~Hz}$ is taken as the fundamental frequency and the harmonic contents were located at the integer multiples of fundamental frequency. From the spectral analysis, it was found that, with the saturation of PV, current harmonics are introduced into the system. It was shown that, other than the fundamental frequency, maximum current is at $450 \mathrm{~Hz}$, i.e., in the $9^{\text {th }}$ harmonic. Levels of individual harmonics are shown in Figure 13, from which it can be concluded that harmonic introductions from all even harmonics are within the safety boundary as stated in the AS4777 standard. However, introductions from $3^{\text {rd }}$ and $9^{\text {th }}$ harmonics surpass the regulatory standard, while introductions from $7^{\text {th }}$ and $15^{\text {th }}$ harmonics just touch the threshold levels. However, harmonic current in the network would be considerably increased with PV saturation.

Moreover, from the experiments it was shown that, for the variation of PV generation and inverter characteristics, minor voltage instability as well as reduction in power factor occur in the network. However, to properly examine these problems, large-scale PV saturation into the network is required. Hence, this study will further examine the potential barriers to large-scale PV saturation into the grid with simulation analysis.

The authors are now developing a simulation model using PSS SINCAL [38] that mimics the experimental setup to evaluate the effects of PV saturation into the grid. Preliminary results from simulation show that voltage instability and harmonic introduction increases with increasing PV saturation. In some cases, these values exceed the regulatory standards.

The final contribution of this study is to develop an integrated platform which will enable researchers and Industry practitioners to effectively and efficiently investigate the impacts of the integration of RE into the future smart grid power system. This proposed tool will be developed by

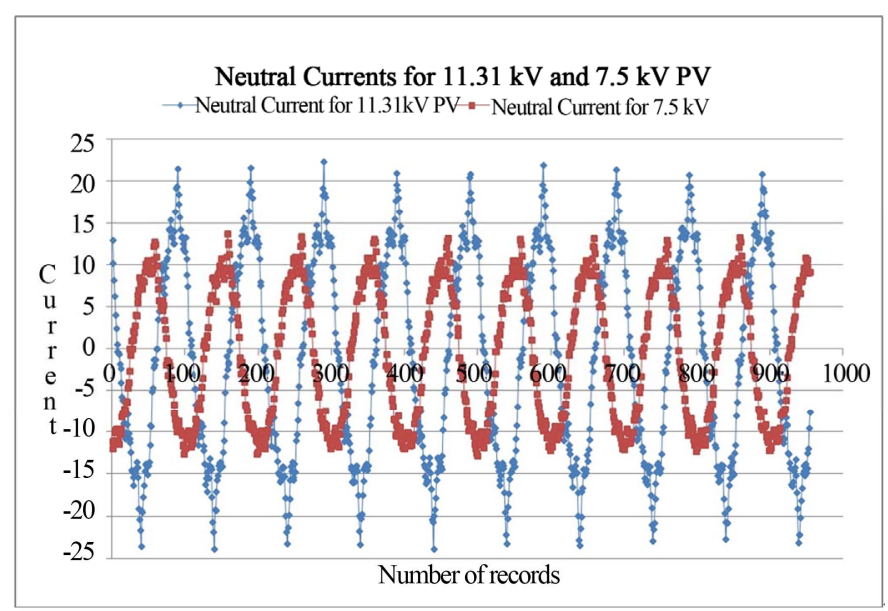

Figure 12. Neutral currents with 11.31 kV and 7.5 PV [37]. 


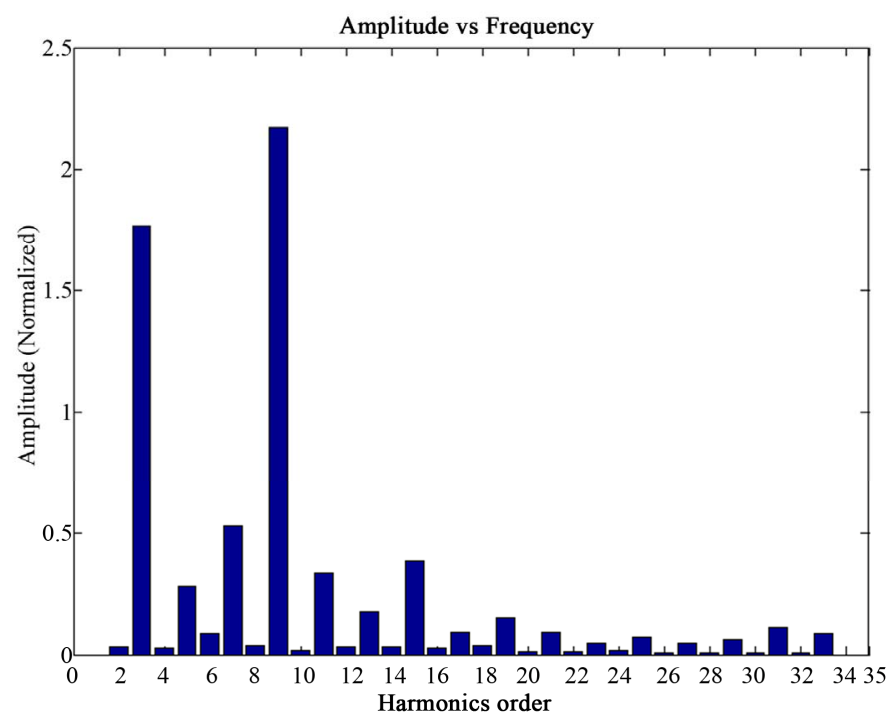

Figure 13. Amplitudes of different harmonics [37].

integrating all of the developed modules discussed throughout this study into an interactive user interface.

\section{Conclusion}

Recent environmental consciousness resulting from conventional power station has encouraged attention on the development of modern smart grid technology and its integration with climate friendly green renewable energy. The use of smart grid operations allows for greater penetration of variable energy sources through more flexible management of the system. Considering the current scenario, substantial research, planning and development work has been undertaken world-wide, especially in Europe, the USA and Australia. The USA declares its mission of "Grid 2030" that connects everyone to an abundant, affordable, clean, efficient and reliable electric power network. The primary national goal of Australia is to increase the use of renewable energy from present levels to 20 percent of total electrical supply by 2020 .

As a work in progress, in this paper a feasibility study was investigated exploring the characteristics and cost analysis of grid connected hybrid RE systems, in which it was clearly observed that RE has significant potentialities. Experiments were carried out to investigate the impacts of RE sources in a smart power network, in particular large-scale PV penetration into the grid. From experimental and simulation analyses, it was observed that voltage fluctuations and harmonic injection increases with the increase of PV penetration. However, this study is still in the introductory stage and needs to be further investigations on the following areas to successfully complete the study:

- Analyze the impacts of large-scale integration of RE sources into the smart power systems.
- Develop integrated platform to monitor continuously the impacts of RE in developing a smart power system for the future.

\section{REFERENCES}

[1] "Smart Grid, Smart City: A New Direction for a New Energy Era,” Technical Report, Department of the Environment, Water, Heritage and the Arts, 2009.

[2] B. Hendricks, "Wired for Progress-Building a National Clean-Energy Smart Grid,” Technical Report, Center for American Progress, 2009.

[3] A. Zahedi, "Developing a System Model for Future Smart Grid,” Proceedings in 2011 IEEE PES Innovative Smart Grid Technologies Conference, ISGT Asia 2011, Perth, 13-16 November 2011, pp. 1-5.

[4] "Proceedings and Outputs of the Workshop for Developing the Australian Smart Grid R\&D Roadmap,” Technical Report: SGA Research Working Group and CSIRO, Sydney, 2009.

[5] X. Fang, S. Misra, G. Xue and D. Yang, "Smart GridThe New and Improved Power Grid: A Survey,” International Journal of IEEE Communications Surveys \& Tutorials, Vol. 14, No. 4, 2011, pp. 944-980.

[6] B. Panajotovic, M. Jankovic and B. Odadzic, "ICT and Smart Grid," Proceedings for the 10th International Conference on Telecommunication in Modern Satellite Cable and Broadcasting Services, Serbia, 5-8 October 2011, pp. 118-121.

[7] “The Smart Grid: An Introduction,” Technical report by US depart of Energy, 2008.

http://energy.gov/oe/downloads/smart-grid-introduction-0

[8] "Grid 2030 — A National Vision for Electricity's Second 100 Years,” US Department of Energy, Office of Electric Transmission and Distribution, July 2003.

[9] “Electric Power Research Institute Intelligrid,” Technical 
Report. http://intelligrid.epri.com/

[10] R. E. Brown, "Impact of Smart Grid on Distribution System Design," Proceedings of IEEE Power and Energy Society General Meeting-Conversion and Delivery of Electrical Energy in the 21st Century, Pittsburg, 20-24 July 2008, pp. 1-4.

[11] GridWise Program, "Rethinking Energy from Generation to Consumption," US Department of Energy, Office of Electric Transmission and Distribution, January 2005.

[12] B. J. Walker, "Renewable Energy \& Smart Grid Interactions," Technical Report: National Grid-The Power of Action, New England Conference of Public Utilities Commissioners, 2009.

[13] “Smart Grids-European Technology Platform,” Technical Report. http://www.smartgrids.eu/documents/vision.pdf

[14] M. Davidson, "Smart Grid Australia: An Overview," Technical Report: Wessex Consult, Australia, 2010.

[15] P. Budde, "Smart Grid Australia Provided the Vision for the Smart Grid/Smart City Project," Smart Grid Australia, October 2010.

[16] "Smart Grid, Smart City," Report: Department of Resources, Energy and Tourism, Australian Government, May 2011.

[17] “Grid Intelligent Grid,” Technical Report, http://www.igrid.net.au/

[18] “Townsville Solar City,” Ergon Energy, Queensland. http://www.townsvillesolarcity.com.au/Home/tabid/36/De fault.aspx.

[19] O. Gol, "Renewable Energy_-Panacea for Climate Change?" Proceedings of ICREPQ'08, Santander, 12-14 March 2008.

[20] Department of Resources, Energy and Tourism, Australian Government, "Clean Energy Initiative Overview," 2011.

http://www.ret.gov.au/Department/Documents/cei/CEI_F act_Sheet.pdf

[21] V. C. Gungor, D. Sahin, T. Kocak, C. Buccella, C. Cecati and G. P. Hancke, "Smart Grid Technologies: Communication Technologies and Standards," IEEE Transactions on Industrial Informatics, Vol. 7, No. 4, 2011, pp. 529538. doi:10.1109/TII.2011.2166794

[22] V. C. Gungor, B. Liu and G. P. Hancke, “Opportunities and Challenges of Wireless Sensor Networks in Smart Grid,” IEEE Transactions on Industrial Electron, Vol. 57, No. 10, 2010, pp. 3557-3564. doi:10.1109/TIE.2009.2039455

[23] L. Wenpeng, D. Sharp and S. Lancashire, "Smart Grid Communication Network Capacity Planning for Power Utilities," Proceedings of IEEE PES Transmission Distribution Conference Exposium, New Orleans, 19-22 April
2010, pp. 1-4.

[24] Q. Yang, J. A. Barria and T. C. Green, "Communication Infrastructures for Distributed Control of Power Distribution Networks," IEEE Transactions on Industrial Informatics, Vol. 7, No. 2, 2011, pp. 316-327. doi:10.1109/TII.2011.2123903

[25] V. C. Gungor, D. Sahin, T. Kocak and S. Ergut, "Smart Grid Communications and Networking,” Turk Telecom, 2011.

[26] IEEE Smart Grid, "Smart Grid Conceptual Framework.” http://smartgrid.ieee.org/smart-grid-framework-diagram

[27] C. W. Potter, A. Archambault and K. Westrick, "Building a Smarter Grid through Better Renewable Energy Information," Proceedings of IEEE/PES Power Systems Conference and Exposition, 15-18 March 2009, pp. 1-5. doi:10.1109/PSCE.2009.4840110

[28] "HOMER Energy." http://www.homerenergy.com/

[29] “HOMER - Analysis of Micropower System Options.” https://analysis.nrel.gov/homer/

[30] G. M. Shafiullah, A. T. Oo, D. Jarvis, S. Ali and P. Wolfs, "Prospects of Renewable Energy-A Feasibility Study in the Australian Context," Journal of Renewable Energy, Elsevier, Vol. 39, No. 1, March 2012.

[31] I. H. Witten and E. Frank, "Data Mining: Practical Machine Learning Tool and Technique with Java Implementation,” Morgan Kaufmann, San Francisco, 2000.

[32] S. Ali and K. A. Smith, "On Learning Algorithm Selection for Classification,” Journal on Applied Soft Computing, Vol. 6, No. 2, 2006, pp. 119-138.

[33] R. Dimov, "Weka: Practical Machine Learning Tools and Techniques with Java Implementations,” Technical Report, University of Saarland, Saarbrücken, 2007.

[34] “Weka 3,” Technical Report, The University of Waikato, New Zealand, 2009.

http://www.cs.waikato.ac.nz/ml/weka/

[35] G. M. Shafiullah, A. M. T. Oo, D. Jarvis, S. Ali and P. Wolfs, "Potential Challenges: Integrating Renewable Energy with the Smart Grid,” Proceedings of Australasian Universities Power Engineering Conference, Christchurch, 5-8 December 2010, pp. 1-6.

[36] “Renewable Energy Integration Facility,” CSIRO. http://www.csiro.au/Outcomes/Energy/Renewable-Energ y-Integration-Facility.aspx

[37] G. M. Shafiullah, A. M. T. Oo, S. Ali, S. Azad, M. Arif and T. Moore, "Experimental Analysis of Harmonics on Utility Grid with PV Penetration,” Proceedings of International Conference on Electrical and Computer Engineering (ICECE 2012), Ottawa, 22-24 August 2012, pp.

[38] PSS Sincal, PSS Product Suite, Siemens. http://www.simtec.cc/sites_en/sincal.asp 